\title{
INTRODUCTION
}

\section{Connecting Research and Patient Care: Lessons from the VA's Quality Enhancement Research Initiative}

\author{
David Atkins, MD, MPH \\ Department of Veterans Affairs, Health Services Research and Development Service (124Q), Washington, DC, USA.
}

J Gen Intern Med 25(Suppl 1):1-2

DOI: $10.1007 / \mathrm{s} 11606-009-1149-8$

(c) Society of General Internal Medicine 2009

$\mathrm{T}$ he challenge of how to speed and sustain improvements in a complex health system continues to be a vexing one. It's a challenge that has become even more urgent because of the current proposals for national health care reform. The success of that reform will depend in large part on whether we can learn how to transform our health care system into one that is more effective, reliable and efficient. The national meeting of the Quality Enhancement Research Initiative (QUERI) of the Department of Veterans Affairs, Veterans Health Administration (VA) in late $2008^{1}$ offered a chance to reflect on what we have learned over a decade of studying and facilitating improvement for priority conditions within the VA. Although there are unique features to the VA due to the patients we serve and our integrated structure, many of the lessons are broadly applicable.

The most obvious lesson is a familiar but painful one: change is hard and often slow. Many of the most impressive improvements that the VA and other health systems have made over the past 10 years-for example, improving cancer screening, immunizations and cardiac care with combinations of reminder systems, performance measurement, education and practice changes-are now behind us. ${ }^{2}$ To maintain improvement going forward, we will have to address new challenges, and the gains may be more modest. In baseball parlance, if QUERI was born with visions of becoming the slugger who belts towering home runs, it has grown up into a solid utility player who scatters singles, infield hits and sacrifice flies. But as any fan knows, you can score more runs by a steady succession of hits than by always swinging for the fences. Meaningful progress is still possible, but it requires that we remain focused on specific goals, work to align all the different parts of the health care system and stay pointed in a consistent direction.

The second lesson relates to the still young discipline of implementation science and translation research that forms the scientific core of QUERI. Implementation science has made important strides and is achieving growing attention, from new journals $^{3}$ and conferences ${ }^{4}$ to the succession of Clinical and Translational Science Awards granted by the National Institutes of Health. At the same time, there still seems to be much more attention on translating basic science into clinical applicationsovercoming the "First Translational Block" (T1)-than on the equally important need to implement proven clinical applica- tions more widely and reliably (T2). ${ }^{5,6}$ If we want to attract more attention, resources and expertise to this effort, however, we need to do a better job of turning what we have learned into tangible tools and guidance for clinical managers and policy makers. It is time to move beyond attempts to develop the perfect theoretical model to explain the "black box" of the implementation process. We have numerous models to help organize and structure our observations and frame more specific hypotheses ${ }^{7}$. Common to all of them is an emphasis on the importance of context-the recognition that the success of any strategy depends critically on the type of change being implemented and the setting in which it is being adopted. For example, two articles in this supplement deal with the importance of "readiness to change" as an influence on success ${ }^{8,9}$. We need additional practical tools to assess such contextual factors and define how we can address those that are modifiable. We also need to learn how to adapt our implementation strategy when we confront non-modifiable barriers to implementation. For example, one of the most consistent findings is that commitment of local leadership is a critical prerequisite for successful implementation. Given that, what is the best way to measure leadership commitment? What, if any, strategies can build commitment of leadership? And what should we do in the absence of that commitment-give up or try to work around it?

A third lesson is that the QUERI model can both learn from and contribute to other approaches to quality improvement in the VA and elsewhere. QUERI has always embraced its dual identity as a research and implementation program ${ }^{10}$. The research component has enabled QUERI to attract experts within the VA who understand the critical clinical issues, are familiar with the complexities of the available data, can conduct the appropriate analyses to tell whether we are making a difference and are sufficiently objective to acknowledge when we aren't. At the same time, to many of our operational partners, "research" carries negative associations of cumbersome and lengthy institutional review processes, detached academic investigators and a priority on publication over sustainable improvement. Much of the quality improvement work in health care is now emphasizing system re-engineering approaches and rapid cycle process improvement ${ }^{11}$. Rather than being in competition, the approaches of QUERI and system redesign can complement each other. Researchers who want to make a difference will need to be willing to "get their hands dirty" and engage partners on the problems they need to solve, within timelines that match their needs, while balancing competing concerns of rigor and relevance. The Cancer Care Collaborative described by Jackson in this supplement is a good example of QUERI working with the Office of Quality and Performance and the Systems Redesign initiative in the VA to tackle specific 
quality issues in cancer care ${ }^{12}$. If we think such types of partnerships are important, we need to find innovative ways to quickly review and fund projects, publish as much of this activity as possible and create viable academic career paths for investigators who mix traditional "discovery-oriented" research with partner-focused activities aimed at solving specific problems ${ }^{13}$.

The final lesson is that implementation strategies and implementation research will need to continue to evolve to meet changing priorities. There are at least three areas that deserve more focus. The first is how to implement interventions to reduce waste and improve value-for example, programs to reduce inappropriate use of high-cost diagnostic imaging or invasive technologies ${ }^{14}$. This process of "de-implementation" is likely to require different approaches than those used to promote uptake of new procedures. However, outside of a few areas such as reducing inappropriate antibiotic use, we know relatively little about addressing "overuse." Second, we need to combine condition-specific improvement approaches with programs that target issues that cut across chronic diseases. Much of the evidence about improvement remains disease-specific. We need better ways to take what we have learned from individual conditions to build programs that improve care for chronic disease more generally. The review of patient self-management programs in this supplement by Damush et al. is an example of such efforts within QUERI ${ }^{15}$. Given the multiple comorbid illnesses of many older patients, designing separate approaches for each condition will only impede our attempts to provide coordinated, patient-centered care. Finally, we need to learn how to use the combination of new technologies available to us to communicate better with patients and coordinate with other providers. The VA has benefited greatly from an advanced electronic health record that has incorporated multiple improvement tools, as reviewed here by Hynes et al. ${ }^{16}$ The article by Williams et al. describes the impact of computerized clinician reminders related to alcohol problems. ${ }^{17}$ But we run the risk of being buried by our successes: in a recent survey of primary care providers in the VA, the proliferation of reminders and clinical alerts was the top problem they wanted addressed (private communication, Madhu Agarwal, September 19, 2009).

Some might worry that the current focus on health care reform will take attention away from quality improvement and implementation research. I think the prospect of real reform, and the challenge of how to pay for it, will only make this work more critical. We will never navigate the challenges of reform unless we bring to bear all we have learned about how to facilitate change in complex organizations to improve quality and value. The deficiencies of our current health care system are front and center in the policy debate-whatever solution emerges, enacting it will require all the help we can provide.

Corresponding Author: David Atkins, MD, MPH; Department of Veterans Affairs, Health Services Research and Development Service (124Q), 810 Vermont Avenue, NW, Washington, DC 20420, USA (e-mail:david.atkins@va.gov).

\section{REFERENCES}

1. QUERI National Meeting 2008: Connecting research and patient care Available at: http://www.queri.research.va.gov/meetings/QUERI08/. Accessed October 2, 2009.

2. Kizer KW, Dudley RA. Extreme makeover: transformation of the veterans health care system. Annu Rev Public Health. 2009;30:313-39.

3. Implementation Science. Available at: http://www.implementa tionscience.com. Accessed October 2, 2009.

4. 3rd annual NIH conference on the science of dissemination and implementation: Methods and measurement. Available at: http:// conferences.thehillgroup.com/obssr/di2010/index.html. Accessed October 2, 2009.

5. Woolf SH. The meaning of translational research and why it matters. JAMA. 2009;299:211-13.

6. Dougherty D, Conway PH. The "3T"s" road map to transform US health care: the "how" of high-quality care. JAMA. 2008;299:2319-21.

7. Damschroder LJ, Aron DC, Keith RE, Kirsh SR, Alexander JA, Lowery JC. Fostering implementation of health services research findings into practice: a consolidated framework for advancing implementation science. Implement Sci. 2009;4:50.

8. Holt DL, Helfrick CD, Hall CG, Weiner BJ. Are you ready? How health professionals can diagnose and create readiness for change. J Gen Intern Med. 2009: 24.

9. Hamilton AB, Cohen AN, Young AS. Organizational readiness in specialty mental health care. J Gen Intern Med. 2009: 24.

10. Stetler CB, Mittman BS, Francis J. Overview of the VA quality enhancement research initiative and QUERI theme articles: QUERI series. Implement Sci. 2008;3:8.

11. Marshall M. Applying quality improvement approaches to health care. BMJ. 2009;339:b3411.

12. Jackson GL, Powell AA, Ordin DL, Schlosser JE, et al. Developing and sustaining quality improvement partnerships in the VA: the colorectal cancer care collaborative. J Gen Intern Med. 2009;24.

13. Shojania KG, Levinson W. Clinicians in quality improvement: a new career pathway in academic medicine. JAMA. 2009;301:766-8.

14. Brook RH. Assessing the appropriateness of care-its time has come. JAMA. 2009;302:997-8.

15. Damush TM, Anderson J, Bosworth H, et al. The implementation of patient self-management programs into veteran health administration: scientific challenges. J Gen Intern Med. 2009;24.

16. Hynes DM, Weddle T, Smith N, Whittier E, Atkins D, Francis J. Use of health information technology to advance evidence-based care: lessons from the VA QUERI Program. J Gen Intern Med. 2009;24.

17. Williams EC, LaphamG, Achtmeyer CE, Volpp B, Kivlahan DR, Bradley KA. Use of an electronic clinical reminder for brief alcohol counseling is associated with resolution of alcohol misuse at follow-up screening. J Gen Intern Med. 2009;24. 